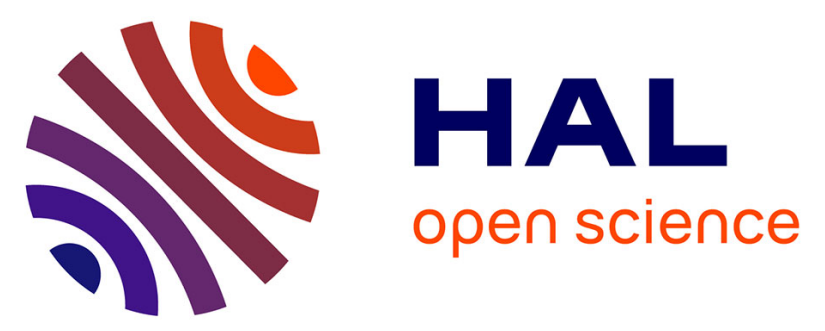

\title{
KCNT1 epilepsy with migrating focal seizures shows a temporal sequence with poor outcome, high mortality and SUDEP
}

Mathieu Kuchenbuch, Giulia Barcia, Nicole Chemaly, Emilie Carme, Agathe Roubertie, Marc Gibaud, Patrick van Bogaert, Anne de Saint Martin, Edouard Hirsch, Fanny Dubois, et al.

\section{To cite this version:}

Mathieu Kuchenbuch, Giulia Barcia, Nicole Chemaly, Emilie Carme, Agathe Roubertie, et al.. KCNT1 epilepsy with migrating focal seizures shows a temporal sequence with poor outcome, high mortality and SUDEP. Brain - A Journal of Neurology , 2019, 142 (10), pp.2996-3008. 10.1093/brain/awz240 . hal-02304375

\section{HAL Id: hal-02304375 \\ https://hal-univ-rennes1.archives-ouvertes.fr/hal-02304375}

Submitted on 9 Mar 2020

HAL is a multi-disciplinary open access archive for the deposit and dissemination of scientific research documents, whether they are published or not. The documents may come from teaching and research institutions in France or abroad, or from public or private research centers.
L'archive ouverte pluridisciplinaire HAL, est destinée au dépôt et à la diffusion de documents scientifiques de niveau recherche, publiés ou non, émanant des établissements d'enseignement et de recherche français ou étrangers, des laboratoires publics ou privés. 


\section{Original Articles \\ KCNT1-Epilepsy of infancy with migrating focal seizures: an identifiable temporal sequence, a poor outcome with high mortality and sudden unex- pected death in epilepsy}

Short running title: Refine the spectrum of EIMFS due to KCNT1 mutation

\section{Authors}

Mathieu Kuchenbuch ${ }^{1,2}$, Giulia Barcia ${ }^{2,3,4}$, Nicole Chemaly ${ }^{2,3}$, Emilie Carme ${ }^{5}$, Agathe Roubertie $^{5}$, Marc Gibaud ${ }^{6}$, Patrick Van Bogaert ${ }^{6}$, Anne de Saint Martin ${ }^{7}$, Edouard Hirsch ${ }^{7}$, Fanny Dubois ${ }^{8}$, Catherine Sarret ${ }^{9}$, Sylvie Nguyen The $\operatorname{Tich}^{10}$, C. Laroche ${ }^{11}$, Vincent des Portes ${ }^{12,13}$, Thierry Billette de Villemeur ${ }^{14}$, Marie-Anne Barthez ${ }^{15}$, Stéphane Auvin ${ }^{16,17}$, Nadia Bahi-Buisson $^{2}$, Isabelle Desguerre ${ }^{2}$, Anna Kaminska ${ }^{2,18}$, Pascal Benquet ${ }^{1}$, Rima Nabbout ${ }^{2,3 *}$.

\section{Affiliations}

1. University Rennes, CHU Rennes (Department of Clinical neurophysiology), Inserm, LTSI (Laboratoire de Traitement du Signal et de l'Image), UMR-1099, F-35000 Rennes, France.

2. Reference centre for rare epilepsies, Department of Pediatric Neurology, Necker Enfants Malades Hospital, Paris Descartes University, Paris, France

3. Institut Imagine, INSERM UMR 1163, Translational research for neurological disorder, France

4. Department of genetics, Necker Enfants Malades Hospital, Imagine Institute, FranceDepartment of Pediatric Neurology, Montpellier University, France

5. Department of Pediatric Neurology, Angers University Hospital, France

6. Department of Pediatric Neurology, Strasbourg University Hospital, France

7. Department of Pediatric Neurology, CHU Grenoble Alpes, F-38000 Grenoble, France.

8. Department of medical genetic, CHU Clermont-Ferrand, France

9. Department of Pediatric Neurology, Lille University Hospital, France

10.Department of Pediatric Neurology, Limoges University Hospital, France 
11.Department of Pediatric Neurology, CNRS UMR 5304, F- 69675 Bron, France

12.Lyon-1 University, F-69008 Lyon, France

13.Department of Pediatric Neurology, Trousseau Hospital, Assistance Publique-Hôpitaux de Paris, France

14.Department of Pediatric Neurology, Tours University Hospital, France

15.Université Paris Diderot, Sorbonne Paris Cité, INSERM UMR1141, 75019 Paris, France;

16.AP-HP, Hôpital Robert Debré, Service de Neurologie Pédiatrique, 75019 Paris, France

17.AP-HP, Necker-Enfants Malades Hospital, Department of Clinical Neurophysiology, Paris, France

\section{* Corresponding author}

Professor Rima Nabbout

Reference centre for rare epilepsies, Department of Paediatric Neurology,

Necker Enfants Malades hospital, 149 rue de Sèvres, 75015, Paris, France

Phone: +33144381536 and fax: +33142192692

E-mail address: rimanabbout@yahoo.com

Number of text pages: 29

Number of words: 4624

Number of words in the abstract: 374

Number of references: 56

Number of figures: 5

Number of tables: 1

Number of supplementary data: 4 + video 


\section{Abstract}

Epilepsy of infancy with migrating focal seizures was first described in 1995. Fifteen years later, KCNT1 gene mutations were identified as the major disease-causing gene of this disease. Currently, the data on epilepsy of infancy with migrating focal seizures associated to KCNT1 mutations are heterogeneous and many questions remain unanswered mainly the prognosis and the long-term outcome especially regarding epilepsy, neurologic and developmental status and the presence of microcephaly. The aim of this study was to assess data from patients with epilepsy in infancy with migrating focal seizures with KCNT1 mutations to refine the phenotype spectrum and the outcome.

We used mind-maps based on medical reports of children followed in the network of the French reference centre for rare epilepsies and we developed families' surveys to assess the long-term outcome.

Seventeen patients were included (age: median: 4 [ $25^{\text {th }}$ percentile: $2-75^{\text {th }}$ percentile: 15$]$ years, sex ratio: 1.4, length of follow-up: 4 [2-15] years). Seventy-one percent started at 6 [1-52] days with sporadic motor seizures $(\mathrm{n}=12)$, increasing up to a stormy phase with long lasting migrating seizures at 57 [30-89] days. The others entered directly this stormy phase at 1 [1-23] days. Ten patients entered a consecutive phase at 1.3 [1-2.8] years where seizures persisted at least daily $(n=8)$, but presented different semiology: brief and hypertonic with a nocturnal $(n=6)$ and clustered $(n=6)$ aspects. Suppression interictal patterns were identified on the EEG $71 \%$ of patients $(n=12)$ sometimes from the first EEG $(n=6)$. Three patients received quinidine without reported efficacy. Long-term outcome was poor with neurological sequelae and active epilepsy except for one patient who had an early and long-lasting seizure free period. Extra cerebral symptoms probably linked with KCNT1 mutation were present like arteriovenous fistula, dilated cardiomyopathy and precocious puberty. Eight patients (47\%) had died at 3 [1.5-15.4] years including three from suspected sudden unexpected death in epilepsy. 
Refining the electro-clinical characteristics and the temporal sequence of epilepsy in infancy with migrating focal seizures should help recognizing this epilepsy. A better knowledge of the outcome allows to deliver clear messages to the families and to better shape the follow-up and the therapies. Extra cerebral involvement should be better investigated especially cardiac system as it might be involved in the high sudden unexpected death in epilepsy prevalence.

Key-word: Migrating Focal Seizure in Infancy, Developmental Epileptic Encephalopathy, Malignant Migrating Partial Seizure in Infancy, Phenotypic spectrum, 


\section{Introduction}

Epilepsy of infancy with migrating focal seizures (EIMFS), initially described in 1995(Coppola et al., 1995), is a rare developmental epileptic encephalopathy (DEE) with an estimated incidence of about 0.11 per 100,000 (Lim et al., 2016). The key features of this syndrome include focal seizures onset in the first six months of life with a specific EEG ictal pattern recognized as "migrating seizure" (Coppola et al., 1995; Barcia et al., 2012; McTague et al., 2013), and progressive developmental delay. Fifteen years after the electro-clinical characterization of EIMFS, mutations of $K C N T 1$, coding a sodium-activated potassium channel (called slack), were reported as the major disease-causing gene (Barcia et al., 2012; Ohba et al., 2015). Mutations of this gene have been also reported in Autosomal Dominant Nocturnal Frontal Lobe Epilepsy (ADNFLE) and Ohtahara syndrome (Heron et al., 2012; Martin et al., 2014). To date, around 60 patients associating $K C N T 1$ mutations and EIMFS are reported with variable and often incomplete information on seizures, EEGs, therapies, MRI and neurodevelopmental status (McTague et al., 2018; Ishii et al., 2013; McTague et al., 2013; Bearden et al., 2014, Mikati et al., 2015b; Møller et al., 2015; Ohba et al., 2015; Mori et al., 2016; Rizzo et al., 2016; de Kovel et al., 2016; Baumer and Sheehan, 2017; Zhang et al., 2017; Jee N et al., 2017; Kawasaki et al., 2017; Madaan et al., 2017; Abdelnour et al., 2018; Numis et al., 2018; Dilena et al., 2018). Many questions remain unanswered, mainly on the prognosis and the long-term outcome.

The aim of this study is to refine the electro-clinical spectrum of patients with EIMFS due to KCNT1 mutations in order to determine the long-term outcome. 


\section{Materials and methods}

\section{Population and data}

We included patients with EIMFS and KCNT1 mutations followed in the network of the French reference centre for rare epilepsies between January 2006 and 2016. EIFMS diagnosis was based on the main features of this syndrome: seizure onset before 6 months, identification of migrating focal seizures, and psychomotor regression following seizure onset (Coppola et al., 1995; Wilmshurst et al., 2000; Gross-Tsur et al., 2004; Gilhuis et al., 2011). We collected all in and out patients' medical reports as well as EEGs and MRI original electronic files. In addition, we contacted all families through a structured questionnaire to have updated data.

Children's anthropometric measures were compared with those of the general population derived from World Health Organization growth charts (https:/www.cdc.gov/growthcharts/) and were expressed in standard deviation (SD). Data are represented as median [25th-75th percentile]. This study was approved by our institution's Ethics Committee and all participants or their legal guardians provided written informed consent.

\section{Data processing}

Medical reports were digitized using an optical character recognition and classified though mind mapping software (Docear (Beel et al., 2011)). Mind Mapping is a visual representation of ideas and information in map form. Deployed around a central idea, they organize information according to a view based on Hierarchy and Association. To obtain a synthetic overall view of each patient, we grouped all data into 8 categories: growth data, medical history, psychomotor development, seizures description, clinical examination, AEDs, EEGs (interictal and ictal) and imaging. Finally, we used these mind mapping to understand EIMFS at a macro level by comparing the different mind maps, to distinguish common features from atypical ones. 
We divided the follow-up of our series in two periods, the first period from seizure onset to the stormy phase and the second initiating after the stormy phase.

\section{Survey development}

We developed a questionnaire for patients who reached the chronic phase. The questionnaire was sent to the family to explore the last 6 months data on 4 axes: general information, overall and neurological condition, seizures and therapies (see supplementary data). 


\section{Results}

\section{Patient characteristics}

Nineteen patients were collected for this study. Seventeen, 10 males and 7 females, were included after the exclusion of two patients due to lack of follow-up data. Two patients had novel KCNT1 mutations not previously reported in EIMFS (c.2688G>A and c.1304C >G) with one c.2688G > A mutation already reported in a patient with ADNFLE. Seven patients were partially described previously without any follow-up data (Barcia et al., 2012; Merdariu et al., 2013) (Table 1 and Fig. 1). Molecular diagnosis was made at 5 [0.7-8.8] years old and before one year in 6 . At the last follow-up, age ranged from 3 months to 19.5 years (median: 4 [25 $5^{\text {th }}$ percentile: $2-75^{\text {th }}$ percentile: 15] years). The number of medical, EEG and MRI reports per patient were 29 [23-33] (from 21 to 70), 16.5 [12.25-19] (from 8 to 30) and 2.5 [2-3] (from 1 to 5), respectively. Five patients had family history of epilepsy ( 2 focal pharmaco-responsive, 2 without additional information and one febrile seizures). Pregnancy and delivery were unremarkable except for one patient born with retroplacental hematoma without neonatal distress. One patient was treated in Neonatal ICU for neonatal apnea, feeding difficulties, hypotonia and laryngomalacia reported as a minor Pierre Robin sequence. Head circumference measurements at birth were $-0.6\left[25^{\text {th }}\right.$ percentile- $75^{\text {th }}$ percentile: $(-0.14)-(-0.84)]$ standard deviations (SD). All the families of patients who entered the chronic phase of this syndrome completed the survey $(n=10 ; 100 \%)$.

\section{First period: from onset to stormy phase}

\section{Seizures characteristics}

Seizure onset was at 6 [1-52] days. Seventy-one percent $(n=12)$ started with sporadic seizures at 9.5 [1.8-54] days associated with clinical manifestations described as spasms in $25 \%(\mathrm{n}=3)$ (Fig. 2). However, the clinical description of infantile spasms was only confirmed in one patient on video-EEG recordings (patient $n^{\circ}$ ) as the two others showed tonic seizures (patient $n^{\circ} 7$ and 14). Seizures involved limbs in $92 \%$ (11 patients: 6 clonic, 4 tonic and 1 tonic-clonic), eyes in $83 \%$ 
( $n=10: 4$ eyes' deviation, 3 fixed gaze and 3 eyes' clonia), head deviation in 50\% and mouth in 50\% ( $\mathrm{n}=6$ : 1 clonic, 1 deviation, 1 with deviation and clonic manifestations and 3 chewing movements). Only $17 \%$ had desaturation $(n=2)$. Patients entered progressively in a stormy phase with focal seizures increasing in frequency, with the EEG showing migrating seizures at 57 [30-89] days. Epileptic spasms tended to disappear before the age of 6 months. Five patients $(n=5,29 \%)$ showed directly at onset the stormy phase at 1 [1-23] days.

\section{EEG data}

The first EEG was realized 5 [1-11] days after the onset of seizures at 25 [12-58] days old. It was considered as normal without any abnormalities in 3 patients (18\%). In the others, the background activities were abnormal in 8 patients showing an increase of slow waves giving a polyrhythmic aspect $(\mathrm{n}=4,24 \%)$ and/or an abnormal discontinuous and asynchronous aspect $(\mathrm{n}=6$, $35 \%)$, only in the quiet sleep $(n=4)$ or throughout the recording $(n=2)$. Multifocal $(n=10,59 \%)$ or focal spikes $(n=3,18 \%)$, mainly in the central, temporal and occipital regions were recorded in 10 patients, including 4 patients with normal background activity. Ictal activity was recorded in 5 patients showing 1 to more than 10 brief seizures with a temporal or occipital onset ( $<2$ minutes) and in two of them, the background was normal. Within two months after the first EEG, all subsequent EEGs showed abnormal background activity. In most cases, background activities of awake EEGs were monotonous, polyrhythmic, slow and poorly spatialized with multifocal spikes. During sleep, spindles were difficult to individualize and $82.4 \%$ of patients had periods from 3 to 40s with diffuse hypo voltage or suppression, in particular during quiet sleep $(n=14)$. This pattern was first reported at 41 [8.5-122] days of life (from birth to 2.5 years old, Fig. 3A and B) and was after this date reported in several EEGs. Electro-clinical spasms were recorded in only one patient confirming epileptic spasms. In 2 other patients, families reported "spasms", but video-EEG recordings showed axial tonic manifestation that evolved into tonic seizures or clonic seizures with no epileptic spasms. 
The EEGs performed during this stormy phase recorded at least 24 [15-35] seizures per patient. Ictal activity consisted of theta monomorphic patterns sometimes preceded by a flattening of the EEG. Seizures were predominant in temporal and occipital areas with inconstant lateralization. For each patient, seizures showed a migrating pattern with a monomorphic theta or alpha ictal activity, beginning on one side and ending on the other (Fig. 3C). Intra-hemispheric migrating seizures were very rarely described in the EEG reports during this period (Fig. 3D).

\section{MRI data}

First MRI was realized 15 [5-30] days after EIMFS onset i.e. at 29 [20-57] days of life. It was normal in $56 \%(\mathrm{n}=9$, supplementary Fig.1A). In the other cases, it showed myelination delay $(n=6)$, thin corpus callosum $(n=5)$, cortico-subcortical atrophy $(n=3)$, and a subdural hematoma $(n=1)$. Only two patients ( ${ }^{\circ} 5$ and 16$)$ in our cohort had only one single early MRI. One MRI was normal (patient $n^{\circ}$ ) while the other showed a thin corpus callosum (patient $n^{\circ} 16$ ).

\section{Second period: chronic phase}

Ten patients have ended the stormy phase by the date of this study (77\%), aged 1.3 [1-2.8] years and entered a second phase. Four patients were still in the active stormy phase (aged from 1.5 to 3.5 years) and three died during the stormy phase (Fig. 2).

\section{Seizures characteristic}

During this phase, seizures were mainly described as tonic (90\%) with often a strident scream $(60 \%)$ with a facial grin and a fixed gaze $(50 \%)$, and sometimes a head or trunk rotation (40\%). Autonomic manifestations were frequent (40\%: chewing, deep breathing, vomiting and mydriasis). Seizures were brief and lasted generally less than one minute (supplementary video). They rarely exceeded 5 minutes. At their last follow-up, two patients (\#6: 16.5 years and \#8 18.4 years) had less than one seizure a week (22\%), the others (age: 12 [9-16] years) had approximately from 3 seizures a week to 25 seizures a day. Some parents were unable to give a number of seizures 
per day but reported them as being numerous. Main trigger factors were stress $(n=6)$, sleep deprivation $(n=4)$ and emotion $(n=2)$. A majority of families reported that these seizures were predominant during sleep $(n=6)$ and had a clustered aspect $(n=6)$.

\section{EEG data}

This subgroup had 23 EEG after the age of 2.5 years (2 [1-3] per patient. EEGs showed an irregular and slow background activity (100\%) with paroxysmal abnormalities in 13 EEGs (57 \%) predominant in temporal $(n=7)$ or frontal $(n=5)$ areas. A total of 23 focal seizures were recorded involving mainly frontal and temporal areas with few clinical signs (Fig.4). Suppression pattern in quiet sleep were reported occasionally in only 2 patients at 5 and 10 years (patients 4 and 6 ). Both had this pattern type recorded before 2.5 years old.

\section{MRI data}

MRI performed after the age of two years ( $n=9$ patients, 13 MRI), showed cortico-subcortical atrophy in all cases often associated with myelination delay $(n=5,56 \%$, supplementary Fig. 1B) and cerebellar atrophy $(n=3,33 \%)$. MRI pattern appeared to be stable over time for MRIs performed after the age of 5 years with no atrophy progression $(n=5)$.

\section{AEDs}

Patient had had a mean of 10 [9-10] antiepileptic trials during this first period. The main AEDs used were benzodiazepines (17; 100\%), vigabatrin (16;94\%), B6 and folinic acid (15; 88\%), ketogenic diet $(14 ; 82 \%)$, phenobarbital $(13 ; 76 \%)$, topiramate $(13 ; 76 \%)$, phenytoin $(13 ; 76 \%)$, valproic acid $(12 ; 71 \%)$, lamotrigine $(6,35 \%)$ and stiripentol $(6,35 \%)$. Therapies showed inconstant and transient efficacy.

During the second period, patients had 1 [1-3] AEDs. A few (1 [0.75-2]) additional AEDs were further tested in addition to the AEDs used in the stormy phase. All have benzodiazepine rescue therapy with a good efficacy on seizures clusters. 
Three patients received quinidine at 15 months, 24 months and 5 years (patient \#14, 11 and 10 respectively), according to the literature data (Mikati et al., 2015a), without any improvement in seizures frequency or neurodevelopment. The quinidine dose was increased up to $45 \mathrm{mg} / \mathrm{kg} / \mathrm{day}$ and the trial lasted for 2 months.

\section{Neurodevelopmental and general outcome}

The majority of patients developed normally before the seizures' onset $(82.4 \%, n=14)$. In the 3 others, 2 entered the stormy phase at day 1 (\# $6 \& 14)$ and the neonatal examination prior to seizures was not performed although they were reported as normal at birth and the last patient (\# 9) had neonatal apnea, feeding difficulties, hypotonia and laryngomalacia and neurological evaluation was difficult prior to seizures onset. Less than 6 months after the onset of EIMFS, all patients presented abnormal neurological examination. All had an axial hypotonia with eyes' contact reported as absent or inconsistent. Psychomotor development was very poor after this except for 1 patient (\#17) who will be detailed below. Forty-one percent of patients ( $\mathrm{n}=7$ ) had hyperkinetic movements affecting the limb $(n=5)$ or/and oral-facial dystonia $(n=2)$. At one year, one-third patients (n=5) had microcephaly under -2 SD (Fig.5). Cardiovascular examination was abnormal for two patients: one had a complex arteriovenous fistula between the hepatic artery and the left portal branch and the other had an unexplained dilated cardiomyopathy.

For patients who entered the second phase (chronic phase), they had follow-up up to 13.6 years [7.2-16.4] with a maximum at 19.5 years. Nine patients had a very similar outcome. All had a microcephaly with a head circumference below -2 SD (Fig.5). After 2.5 years of age, all had a spastic tetraparesis and a marked axial hypotonia. Four patients were able to hold their head up, but none acquired sitting position. Only one patient was able to hold the objects. Patients had eye contact and were able to communicate with their parents by modulating their vocals and one was able to repeat "mama". Crying was almost the only other mean of communication and none had acquired pointing, preverbal or verbal language. The sphincter control was absent, and all showed 
urinary and fecal incontinence. Six patients had a gastrostomy due to difficulty to thrive and swallowing disorders leading to frequent respiratory infections. The 3 others needed finely ground food. Eight patients had a severe scoliosis requiring orthopedic orthotics. Two already underwent scoliosis surgery and this is under discussion for the remaining five. In one girl (patient $\mathrm{n}^{\circ} 11$ ), precocious puberty has been reported (pubic hair growth) at age 5 .

One patient had a different outcome (patient 17). This patient have been already reported before the KCNT1 mutation discovery and met all the criteria for inclusion in this study (Merdariu et al., 2013). She had, from 9 months and till 32 months, a seizure-free period with a combination of levetiracetam, clobazam and stiripentol. During this period, she acquired some psychomotor skills: crawling, sitting, developing social interaction. Development was slow but constant. She was able to walk at 35 months of age. Seizures reappeared at 32 months, initially consisting in loss of awareness episodes with fixed gaze. Progressively, seizures resembled those of the whole cohort described above (waking up with a scream, then stiffening, drooling, clonic movement of one or the 4 limbs, ocular revulsion, deflection of the head and vomiting with a duration usually less than 1 minute). At 8 years old, she had a mean of ten seizures per months. Seizures showed similar characteristics to those of the other patients during the chronic phase. They were triggered by stress, sleep deprivation $(n=4)$ and emotion, predominant during the sleep with a clustered aspect and a frontal onset. At her last follow-up at eight years, she had normal head circumference. She had a fairly good communication skills and was able to address to her mother mainly simple sentences as "Mommy, I want my computer" or "I love you mommy". However, she didn't acquired day or night cleanliness and has a tendency to echolalia and presents with Autism spectrum disorder with SD spectrum abnormal stereotyped movements of the hands and swings and difficulties in interacting and communicating with others and mainly with peers. She had spastic feet with 
Achilles tendon retractions. She was on stable AEDs therapy: Levetiracetam, clobazam and stiripentol. There was no psychometric test available for this patient. However, the referral pediatric neurologist of this patient reported a severe intellectual disability clinically.

\section{Survival and causes of death}

Eight patients from our cohort died at the time of this study at 3 [1.5-15.4] years.

Four patients died in the stormy phase. For 2 of them, death occurred at 2.7 and 18 months at PICU due to sepsis and hemodynamic comorbidities (patient \#15 and 5). Limitation of care was accepted by the family. The last two patients died from a probable Sudden Unexpected Death in Epilepsy (SUDEP) at 1.5 years and 3.2 years old (patient $n^{\circ} 7$ and $\left.n^{\circ} 13\right)$.

Four patients deceased during the chronic phase. The first from probable SUDEP at age of 2.8 years old (\#9) and the 3 others from respiratory failure at 15, 16.5 and 19.5 years after frequent respiratory infections (\#2, 4 and 6). The oldest patient currently alive in this cohort is 18.4 years old (\#8). 


\section{Discussion}

Our study provides a detailed picture of the phenotype and outcome of patients with EIMFS and KCNT1 mutations. Data reported so far in the literature of EIMFS patients with KCNT1 mutations address mainly younger patients ( 0.25 to 8.1 years, median follow-up: 1.9 [1.2-3.5] years versus 0.25 to 19.4 years, median follow-up: 4 [2-15] years, in our study). Data as for head circumference, MRI and EEG are rarely detailed (supplementary table 1). Our study allowed to identify a temporal sequence with 3 consecutive phases, to expand the phenotype outside the central nervous system (CNS) and to bring data about the long-term outcome and SUDEP in a large cohort of patients presenting this rare condition.

In the initial description, EIMFS was described as a 3-phases syndrome (Coppola et al., 1995): sporadic seizures phase (inconstant, starting in the first 6 months), stormy phase with migrating seizures (starting at 1-12 months) and a relatively seizure-free (at age ranging from 1 to 5 years) period. This three stages epilepsy description reminds other epileptic encephalopathies such as DEE with CDKL5 mutations (Bahi-Buisson et al., 2008).

. However, almost one third of patients entered the stormy phase without the sporadic seizures phase. Both groups evolved to a chronic phase around 1.3 [1-2.8] years. Epilepsy at this phase remained active with daily seizures in $80 \%$ of them in opposite to the initial description of the third phase as a " relatively seizure-free period" (Coppola, 2009). We used the term "stabilization period" rather than the "relatively seizure-free period". Seizures in this phase present a shorter duration and a modification in their semiology as they were mostly tonic with few clonic components and predominant in sleep. These changes might explain a better tolerance by the families and the previous labelling as "almost seizure free period".

The presence of an acquired microcephaly is described in EMFSI (Coppola, 2009). Only two longitudinal studies of 7 patients with unknown etiology reported the growth of head circum- 
ference (Marsh et al., 2005; Hahn et al., 2007). We showed a high prevalence of acquired microcephaly with chronological landmarks. Microcephaly appeared with a significant delay compared to seizures and psychomotor regression. It was present in $40 \%$ of patients under 1 year compared to $90 \%$ after 3 years. The only patient who did not have a microcephaly after the age of two had the best neurological outcome.

Two aspects of the EEG in our study were of interest: the presence of suppression-burst and the EEG patterns in the stabilization period. Two patients had a burst suppression pattern as early as the initial EEG associated with focal seizures, suggesting Ohtahara syndrome (OS) diagnosis (Ohtahara and Yamatogi, 2006). KCNT1 mutation have been previously described in one patient with OS (Martin et al., 2014). This pattern of suppression periods in EIMFS had been reported, before 15 months, in 13 patients with KCNT1 mutations including similar proportion in a recent study (8/10 patients versus 13/17 in our population) (Ohba et al., 2015; Selioutski et al., 2015; McTague et al., 2018). However, we show its occurrence after the age of 1 year and its high prevalence in quiet sleep. One possible explanation could be that KCNT1 channels would be implicated in the wake-sleep regulation. In a recent study about modeling the sleep regulation, KCNT1 current and the neural gain are the two key parameters implicated in the transition between wakefulness and the different sleep stage and computational modelling suggests that KCNT1 conductance might have strong influence on non-REM sleep (Costa et al., 2016).

During the stabilization period, EEGs were constantly abnormal with an irregular and slow background rhythm associated with frontal and temporal paroxysmal abnormalities and seizures. Seizures occurred often in sleep with clusters and showed frontal or frontal-temporal origin when they were recorded.

Thus, for the same patient, the EEG pattern may initially support OS diagnosis with a suppression-burst pattern. Then migrating focal seizures are recorded with an interictal EEG pattern that becomes more continuous keeping a suppression aspect in quiet sleep. And finally, as the 
patient grows older, he may have exclusively frontal and frontal-temporal sleep epileptic seizures. This sequence might question a possible continuum between the three main epileptic syndromes associated with KCNT1 mutations, i.e.: OS, EIMFS and ADNFLE. Further EEG studies with additional patients including other epilepsy phenotypes with KCNT1 mutations can better explore this EEG-age correlation.

In human, the expression of RNA related to KCNT1 gene are not restricted to brain and are also localized in spleen, lungs, skeletal muscle, gonads and in particular in ovarian and placental tissues (supplementary Fig.2)(The Human Protein Atlas, n.d.; Uhlén et al., 2015). In this cohort, two patients had cardiovascular abnormalities: complex arteriovenous fistula and a dilated cardiomyopathy with negative etiological tests. In addition, one patient was born in a context of retroplacental hematoma and had a subdural hematoma at 3 months without any reported etiology. Abnormal shunt between systemic and pulmonary systems were reported in 3 patients (Kawasaki et al., 2017) and 2 others had subdural hematoma or hygroma on MRI (Ohba et al., 2015). KCNT1 mutations were also reported in 2 patients with Brugada syndrome (Juang et al., 2015). We may suggest vascular and cardiac malformations as part of the clinical spectrum of KCNT1 mutation. One girl in our cohort presented a precocious puberty. Similar data have already been reported in 3 other patients with this syndrome (Møller et al., 2015). The prevalence of precocious puberty in patients with EIMFS and KCNT1 mutation therefore seemed higher than in general population and (25 and 5 per 10,000 for girls and boys, respectively among children under 10 years in the general population) and might be even higher than the prevalence in children with neurodevelopmental disability (20 times higher than the general population) (Siddiqi et al., 1999; Teilmann, 2005). AEDs could be causal but the age of puberty in 256 girls with epilepsy and AEDs treatment showed no significant difference (Svalheim et al., 2006). We suggest that the mutation per se, knowing the important expression of KCNT1 gene in ovarian and pituitary gland (supplementary Fig.2), can be involved in precocious puberty as in other genetic syndromes (Katzos et al., 2004; 
Saletti et al., 2009). Finally, patients show severe delay in gross motor function with a severe hypotonia. Since KNCT1 gain of function lead to a disruption of motoneuronal functions in fly model (Ehaideb et al., 2017), we cannot exclude that hypotonia can have a multi-origin, central with the strong expression of KCNT1 in cortex and cerebellar tissue (supplementary Fig.2) with the presence of cerebellar atrophy on MRIs of some of our patients and peripheral with the possible involvement of the neuromuscular junction. Such dual disorders of the CNS and the neuromuscular junction were also reported in Dravet syndrome, another DEE caused by mutations in SCN1A (Gitiaux et al., 2016).

In this series, 6 patients had the R428Q protein change, four the $\mathrm{R} 474 \mathrm{H}$ or $\mathrm{R} 474 \mathrm{C}$ mutations and 3 the A934T mutation. At first glance, we were unable to establish genotype-phenotype correlations with respect to age of onset of seizures, age of deaths, etiology of death, distribution of disease stages, EEGs patterns, MRIs or response to antiepileptic therapy. However, more cases would be needed to produce statistics and determine whether or not these correlations are present.

The long-term outcome of patients with EIMFS due to KCNT1 mutations in our cohort is poor with major motor and intellectual delay and pharmacoresistant epilepsy. One patient in our cohort had a better outcome with language acquisition and no gross motor deficit. She had a relatively late onset of epilepsy ( 8 weeks) with a long and early seizure free-periods (from 9 months to 32 months). Her mutation was also reported in one patient with ADNFLE without intellectual disability (Heron et al., 2012) although having a 10-fold increase of peak current of slack (Kim and Kaczmarek, 2014). Another patient reported in the literature (c.1283G>A; p.Arg428Gln) seems to have a good outcome with improvement of cognition after seizures control and treatment with quinidine at 25 months (Mikati et al., 2015b). These 2 patients did not show a common mutation and their mutation was not in the same domain. Three patients in our cohort treated with this drug did not show an improvement in seizures frequency or psychomotor development, although displaying two factors associated with possible good response to this drug: young age and EIMFS 
phenotype (Chong et al., 2016; Abdelnour et al., 2018). In a recent paper, the early use of quinidine, in two patient at 3 and 16 months with KCNT1 mutations and EIMFS, reduced seizures by $90 \%$ and improved quality of life without improving psychomotor development (Dilena et al., 2018). Another retrospective multicenter series on quinidine treatment in 20 patients with KCNT1 epilepsy showed that quinidine was ineffective in $40 \%$ and even worsened epilepsy in $15 \%$. However, the dose and the maximum concentration of quinidine varied widely from patient to patient and sustained efficacy, i.e. lasted at least 3 months, was judged by the evolution in clinically countable seizures assessed by the physician or family (Fitzgerald et al., 2019) .These data highlighted the need of multicenter prospective studies to establish a consensus protocol for quinidine treatment modalities and outcome evaluation.

Eight patients in our series died at a median age of 3 years. The mortality rate in our cohort was almost 50\% (8/17). Three had probable SUDEP leading to a SUDEP prevalence of $17 \%$. A few studies in the literature reported long term follow up and SUDEP prevalence in EIMFS. SUDEP have been reported in one patient with ADNFLE related to KCNT1 mutations and in 11 patients with EIMFS out of $152(7 \%)$ without known mutations or with mutations in other genes (Gross-Tsur et al., 2004; Hmaimess et al., 2006; Freilich et al., 2011; Fasulo et al., 2012; McTague et al., 2013; Milh et al., 2013; Howell et al., 2015; Lim et al., 2015; Møller et al., 2015). Based on these data, the rate of SUDEP in EIFMS in general seems not far from that of Dravet syndrome and even higher than Dravet in EIFMS with KCNT1. Some authors hypothesized that SUDEP in this population could be the result of the gain-of-function of KCNT1 mutation in the heart (Møller et al., 2015; Lim et al., 2016). Indeed, IKNa currents were firstly described in mammalian cardiomyocytes (Kameyama et al., 1984). However, the high level of death and SUDEP urges to discuss this issue with the families. 
Our study shows some limitations. It is a retrospective study based on medical reports and families' questionnaires. The number of available data was extremely high and sorting and selection of data were done using mind mapping, to obtain an overview of the different characteristics and exams of patients. This might have added selection bias and it is likely that in the future deeplearning approaches or registries will be able to establish a more accurate phenotype in homogenous cohort in an unsupervised manner. This study was not aimed to study SUDEP and mortality and we might have overestimated this prevalence.

To conclude, the diagnosis of patients with EIMFS can be difficult and lead to a real odyssey for physicians and families. Refining the electro-clinical characteristics and the temporal sequence should help to establish the diagnosis of EIMFS. The identification of EEG markers characteristic of seizure patterns will improve further this diagnosis (Kuchenbuch et al., 2018). The poor prognosis of this DEE requires an urgent development of trials that should be used early at onset as the early control of seizures might improve the prognosis but should also be tested at later stages as epilepsy remains active in the chronic phase of this syndrome. Extra cerebral involvement should be better investigated especially cardiac system that might add to the high SUDEP prevalence.

\section{Data availability}

The raw data that support the findings of this study are available from the corresponding authors, upon request.

\section{Acknowledgements}

The data used to design supplementary figure 2 were from: the GTEx Portal on 01/16/18. The Genotype-Tissue Expression (GTEx) Project was supported by the Common Fund of the Office of the Director of the National Institutes of Health, and by NCI, NHGRI, NHLBI, NIDA, NIMH, and NINDS. The authors thank all the participants and their families. We thank Domitille 
Parent for her involvement in sorting the patients' data and Caroline Wenzel for her follow-up of the families' survey.

\section{Funding}

This work was supported by funds from the French Pediatric Society ( $\mathrm{PhD}$ one year grant) and the French Institute of Health and Medical Research (PhD 2 years' grant: poste d'accueil Inserm, MK). This work was carried out with the support of the Institute of Clinical Neurosciences in Rennes (INCR).

\section{Competing interests}

The authors report no competing interests.

\section{Supplementary material}

Supplementary Video: Homemade video of seizure in a 12-years old boy with EIMFS due to KCNT1.

Supplementary table: Description of the 62 patients associating KCNT1 mutation and EIMFS in the literature

Supplementary figure 1: MRI at 1 month (A) and at 29 months (B) in the same patient Supplementary figure 2: Main RNA expressions of KCNT1 gene in the different human tissue from human protein atlas.

\section{Figures Legends}

Figure 1: Flowchart of patients' outcome 
Phase 1 (orange) corresponds to the gradual increase in sporadic focal seizures. Phase 2 (red) represents the stormy phase of this syndrome and included migrating seizures. Phase 3 (yellow) is considered as the consolidation phase. One patient presented a seizure-free period (white) between the 2nd and 3rd phase. *corresponded to patients who were dead at the date of the study.

\section{Figure 3: Examples of EEG patterns in patients with EIMFS.}

Interhemispheric migrating seizures (A) and intrahemispheric migrating seizures (B). Suppression patterns during quiet sleep on EEG at 7.5 months (C) and 2.5 years (D). Filters: high pass: $0.01 \mathrm{~Hz}$ and low pass: $35 \mathrm{~Hz}$

\section{Figure 4: EEG ictal patterns at age of 7 years in the consolidation phase (patient $\mathbf{n}^{\circ} 10$ )}

Seizure started with a flattening in the right fronto-central region $(*)$ with rapid diffusion and bilateralisation to all channels. Clinically, this seizure occurred during sleep and corresponded to an asymmetrical tonic seizure (band-pass filter: $0.5-75 \mathrm{~Hz}$ )

Figure 5: Head circumference growth of this series compared to normal population standards.

After one year, one-third of patients had a microcephaly. However, this proportion increased to $90 \%$ at 3 years. It was interesting to note that the only patient who didn't have microcephaly is the patient who had a seizure free period during the first months of life and showed the best prognosis. 



\section{References}

Abdelnour E, Gallentine W, McDonald M, Sachdev M, Jiang Y-H, Mikati MA. Does age affect response to quinidine in patients with KCNT1 mutations? Report of three new cases and review of the literature. Seizure 2018; 55: 1-3.

Bahi-Buisson N, Kaminska A, Boddaert N, Rio M, Afenjar A, Gérard M, et al. The three stages of epilepsy in patients with CDKL5 mutations. Epilepsia 2008; 49: 10271037.

Barcia G, Fleming MR, Deligniere A, Gazula V-R, Brown MR, Langouet M, et al. De novo gain-of-function KCNT1 channel mutations cause malignant migrating partial seizures of infancy. Nat Genet 2012; 44: 1255-9.

Baumer FM, Sheehan M. Quinidine-associated skin discoloration in KCNT1 associated pediatric epilepsy. Neurology 2017; 89: 2212-2212.

Bearden D, Strong A, Ehnot J, DiGiovine M, Dlugos D, Goldberg EM. Targeted treatment of migrating partial seizures of infancy with quinidine. Ann Neurol 2014; 76: 457-61.

Beel J, Gipp B, Langer S, Genzmehr M. Docear: an academic literature suite for searching, organizing and creating academic literature. In: Proceeding of the 11th annual international ACM/IEEE joint conference on Digital libraries - JCDL '11. New York, New York, USA: ACM Press; 2011. p. 465

Chong PF, Nakamura R, Saitsu H, Matsumoto N, Kira R. Ineffective quinidine therapy in early onset epileptic encephalopathy with KCNT1 mutation. Ann Neurol 2016; 79: 502-503. 
Coppola G. Malignant migrating partial seizures in infancy: an epilepsy syndrome of unknown etiology. Epilepsia 2009; 50 Suppl 5: 49-51.

Coppola G, Plouin P, Chiron C, Robain O, Dulac O. Migrating partial seizures in infancy: a malignant disorder with developmental arrest. Epilepsia 1995; 36: 1017-1024.

Costa MS, Born J, Claussen JC, Martinetz T. Modeling the effect of sleep regulation on a neural mass model. J Comput Neurosci 2016; 41: 15-28.

Dilena R, DiFrancesco JC, Soldovieri MV, Giacobbe A, Ambrosino P, Mosca I, et al. Early Treatment with Quinidine in 2 Patients with Epilepsy of Infancy with Migrating Focal Seizures (EIMFS) Due to Gain-of-Function KCNT1 Mutations: Functional Studies, Clinical Responses, and Critical Issues for Personalized Therapy. Neurotherapeutics 2018; 15: 1112-1126.

Ehaideb SN, Decker GT, Smith P, Davis D, Zhang B. Novel Compensatory Mechanisms Enable the Mutant KCNT1 Channels to Induce Seizures. bioRxiv 2017: 191171.

Fasulo L, Saucedo S, Cáceres L, Solis S, Caraballo R. Migrating focal seizures during infancy: a case report and pathologic study. Pediatr Neurol 2012; 46: 182-4.

Fitzgerald MP, Fiannacca M, Smith DM, Gertler TS, Gunning B, Syrbe S, et al. Treatment Responsiveness in KCNT1-Related Epilepsy. Neurotherapeutics 2019: 1-10.

Freilich ER, Jones JM, Gaillard WD, Conry J a, Tsuchida TN, Reyes C, et al. Novel SCN1A mutation in a proband with malignant migrating partial seizures of infancy. Arch Neurol 2011; 68: 665-671.

Gilhuis HJ, Schieving J, Zwarts MJ. Malignant migrating partial seizures in a 4month-old boy. Epileptic Disord 2011; 13: 185-187. 
Gitiaux C, Chemaly N, Quijano-Roy S, Barnerias C, Desguerre I, Hully M, et al. Motor neuropathy contributes to crouching in patients with Dravet syndrome. Neurology 2016; 87: 277-281.

Gross-Tsur V, Ben-Zeev B, Shalev RS. Malignant migrating partial seizures in infancy. Pediatr Neurol 2004; 31: 287-90.

Hahn A, Heckel M, Neubauer BA. Pronounced microcephaly in a patient with malignant migrating partial seizures in infancy. Epileptic Disord 2007; 9: 94-97.

Heron SE, Smith KR, Bahlo M, Nobili L, Kahana E, Licchetta L, et al. Missense mutations in the sodium-gated potassium channel gene KCNT1 cause severe autosomal dominant nocturnal frontal lobe epilepsy. Nat Genet 2012; 44: 1188-90.

Hmaimess G, Kadhim H, Nassogne M-C, Bonnier C, van Rijckevorsel K. Levetiracetam in a neonate with malignant migrating partial seizures. Pediatr Neurol 2006; 34: 55-9.

Howell KB, McMahon JM, Carvill GL, Tambunan D, Mackay MT, RodriguezCasero V, et al. SCN2A encephalopathy: A major cause of epilepsy of infancy with migrating focal seizures. Neurology 2015; 85: 958-66.

Ishii A, Shioda M, Okumura A, Kidokoro H, Sakauchi M, Shimada S, et al. A recurrent KCNT1 mutation in two sporadic cases with malignant migrating partial seizures in infancy. Gene 2013; 531: 467-471.

Jee N, Ko A, Kim SH, Lee JS, Kim HD, Lee ST, et al. Quinidine Trial in a Patient with Epilepsy of Infancy with Migrating Focal Seizure and KCNT1 Mutation. J korean child Neurol Soc 2017; 25: 169-173.

Juang J-MJ, Lu T-P, Lai L-C, Ho C-C, Liu Y-B, Tsai C-T, et al. Disease-Targeted 
Sequencing of Ion Channel Genes identifies de novo mutations in Patients with NonFamilial Brugada Syndrome. Sci Rep 2015; 4: 6733.

Kameyama M, Kakei M, Sato R, Shibasaki T, Matsuda H, Irisawa $H$. Intracellular $\mathrm{Na}+$ activates a K+ channel in mammalian cardiac cells. Nature 1984; 309: 354-6.

Katzos G, Triantafyllou P, Gombakis N, Sofocleous C, Zafeiriou DI. Thelarche variant in a girl with Angelman syndrome. Brain Dev 2004; 26: 339-341.

Kawasaki Y, Kuki I, Ehara E, Murakami Y, Okazaki S, Kawawaki H, et al. Three Cases of KCNT1 Mutations: Malignant Migrating Partial Seizures in Infancy with Massive Systemic to Pulmonary Collateral Arteries. J Pediatr 2017

Kim GE, Kaczmarek LK. Emerging role of the KCNT1 Slack channel in intellectual disability. Front Cell Neurosci 2014; 8: 209.

de Kovel CGF, Brilstra EH, van Kempen MJA, van't Slot R, Nijman IJ, Afawi Z, et al. Targeted sequencing of 351 candidate genes for epileptic encephalopathy in a large cohort of patients. Mol Genet Genomic Med 2016; 4: 568-580.

Kuchenbuch M, Benquet P, Kaminska A, Roubertie A, Carme E, de Saint Martin A, et al. Quantitative analysis and EEG markers of KCNT1 epilepsy of infancy with migrating focal seizures. Epilepsia 2018

Lim BC, Hwang H, Kim H, Chae JH, Choi J, Kim KJ, et al. Epilepsy phenotype associated with a chromosome 2q24.3 deletion involving SCN1A: Migrating partial seizures of infancy or atypical Dravet syndrome? Epilepsy Res 2015; 109: 34-39.

Lim CX, Ricos MG, Dibbens LM, Heron SE. KCNT1 mutations in seizure disorders: the phenotypic spectrum and functional effects. J Med Genet 2016; 53: 217-25.

Madaan P, Jauhari P, Gupta A, Chakrabarty B, Gulati S. A quinidine non 
responsive novel KCNT1 mutation in an Indian infant with epilepsy of infancy with migrating focal seizures. Brain Dev 2017

Marsh E, Melamed SE, Barron T, Clancy RR. Migrating partial seizures in infancy: Expanding the phenotype of a rare seizure syndrome. Epilepsia 2005; 46: 568-572.

Martin HC, Kim GE, Pagnamenta AT, Murakami Y, Carvill GL, Meyer E, et al. Clinical whole-genome sequencing in severe early-onset epilepsy reveals new genes and improves molecular diagnosis. Hum Mol Genet 2014; 23: 3200-11.

McTague A, Appleton R, Avula S, Cross JH, King MD, Jacques TS, et al. Migrating partial seizures of infancy: expansion of the electroclinical, radiological and pathological disease spectrum. Brain 2013; 136: 1578-91.

McTague A, Nair U, Malhotra S, Meyer E, Trump N, Gazina E V, et al. Clinical and molecular characterization of KCNT1-related severe early-onset epilepsy. Neurology 2018; 90: e55-e66.

Merdariu D, Delanoë C, Mahfoufi N, Bellavoine V, Auvin S. Malignant migrating partial seizures of infancy controlled by stiripentol and clonazepam. Brain Dev 2013; 35: $177-80$.

Mikati MA, Jiang Y, Carboni M, Shashi V, Petrovski S, Spillmann R, et al. Quinidine in the treatment of KCNT1 positive epilepsies. Ann Neurol 2015: n/a-n/a.

Mikati MA, Jiang YH, Carboni M, Shashi V, Petrovski S, Spillmann R, et al. Quinidine in the treatment of KCNT1-positive epilepsies. Ann Neurol 2015; 78: 995-999.

Milh M, Falace A, Villeneuve N, Vanni N, Cacciagli P, Assereto S, et al. Novel compound heterozygous mutations in TBC1D24 cause familial malignant migrating partial seizures of infancy. Hum Mutat 2013; 34: 869-72. 
Møller RS, Heron SE, Larsen LHG, Lim CX, Ricos MG, Bayly MA, et al. Mutations in KCNT1 cause a spectrum of focal epilepsies. Epilepsia 2015; 56: e114-e120.

Mori T, Imai K, Oboshi T, Fujiwara Y, Takeshita S, Saitsu H, et al. Usefulness of ketogenic diet in a girl with migrating partial seizures in infancy. Brain Dev 2016; 38: 601604.

Numis AL, Nair U, Datta AN, Sands TT, Oldham MS, Patel A, et al. Lack of response to quinidine in KCNT1-related neonatal epilepsy. Epilepsia 2018; 59: 18891898.

Ohba C, Kato M, Takahashi N, Osaka H, Shiihara T, Tohyama J, et al. De novo KCNT1 mutations in early-onset epileptic encephalopathy. Epilepsia 2015; 56: e121e128.

Ohtahara S, Yamatogi Y. Ohtahara syndrome: With special reference to its developmental aspects for differentiating from early myoclonic encephalopathy. Epilepsy Res 2006; 70: 58-67.

Rizzo F, Ambrosino P, Guacci A, Chetta M, Marchese G, Rocco T, et al. Characterization of two de novo KCNT1 mutations in children with malignant migrating partial seizures in infancy. Mol Cell Neurosci 2016; 72: 54-63.

Saletti V, Canafoglia L, Cambiaso P, Russo S, Marchi M, Riva D. A CDKL5 mutated child with precocious puberty. Am J Med Genet Part A 2009; 149: 1046-1051.

Selioutski O, Seltzer LE, Burchfiel J, Paciorkowski AR, Erba G. Characteristic Features of the Interictal EEG Background in 2 Patients with Malignant Migrating Partial Epilepsy in Infancy. J Clin Neurophysiol 2015; 32: e23-e29.

Siddiqi SU, Van Dyke DC, Donohoue P, McBrien DM. Premature sexual 
development in individuals with neurodevelopmental disabilities. Dev Med Child Neurol 1999; 41: 392-395.

Svalheim S, Taubøll E, Bjørnenak T, Røste LS, Mørland T, Sætre ER, et al. Onset of epilepsy and menarche-Is there any relationship? Seizure 2006; 15: 571-575.

Teilmann G. Prevalence and Incidence of Precocious Pubertal Development in Denmark: An Epidemiologic Study Based on National Registries. Pediatrics 2005; 116 : $1323-1328$.

The Human Protein Atlas. Tissue expression of KCNT1 [Internet]. Available from: https://www.proteinatlas.org/ENSG00000107147-KCNT1/tissue

Uhlén M, Fagerberg L, Hallström BM, Lindskog C, Oksvold P, Mardinoglu A, et al. Proteomics. Tissue-based map of the human proteome. Science 2015; 347: 1260419.

Wilmshurst JM, Appleton B, Grattan-smith PJ. MPSI: two New Cases. J Child Neurol 2000; 15: 717-722.

Zhang Q, Li J, Zhao Y, Bao X, Wei L, Wang J. Gene mutation analysis of 175 Chinese patients with early-onset epileptic encephalopathy. Clin Genet 2017; 91: 717724. 


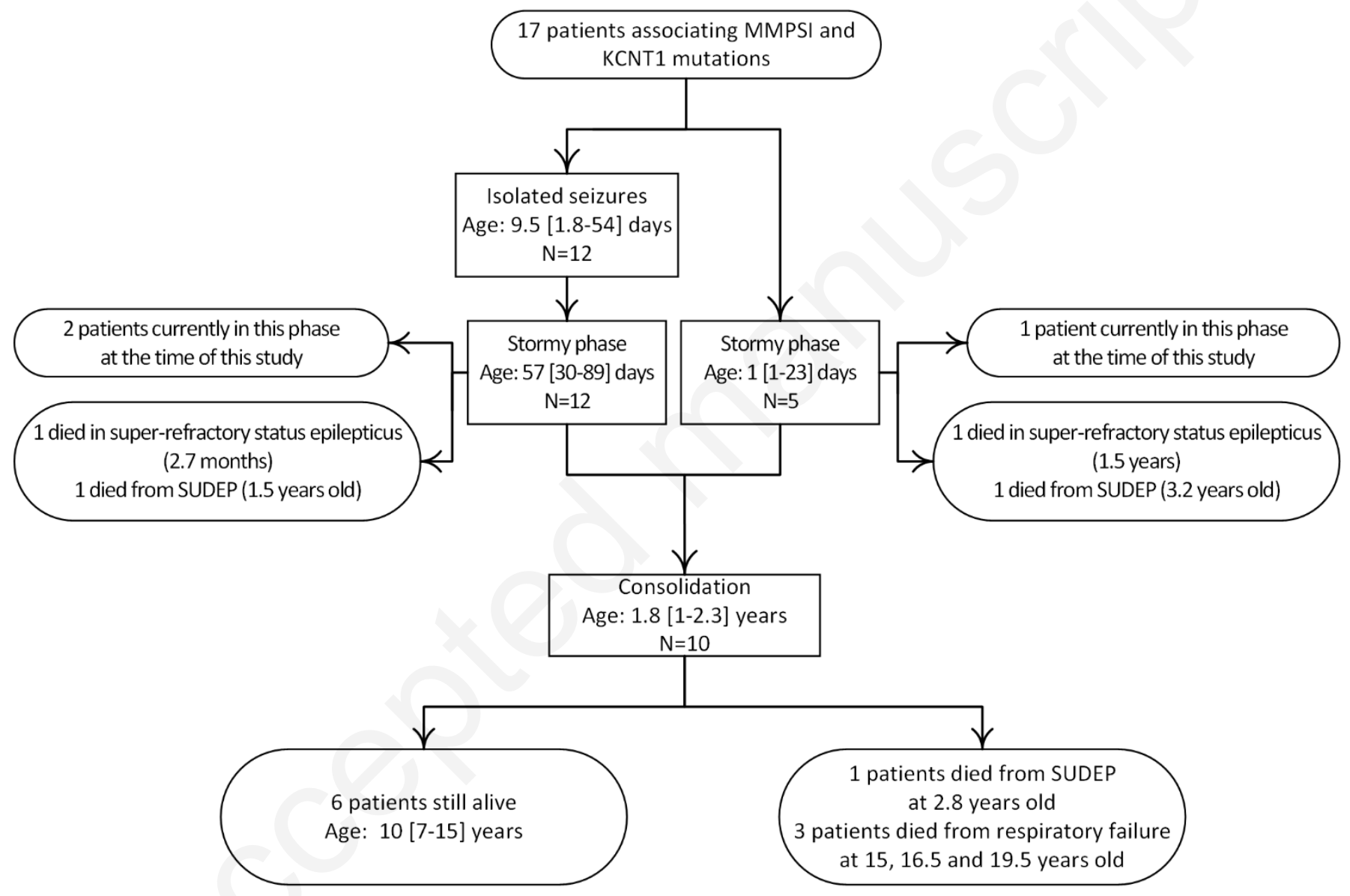




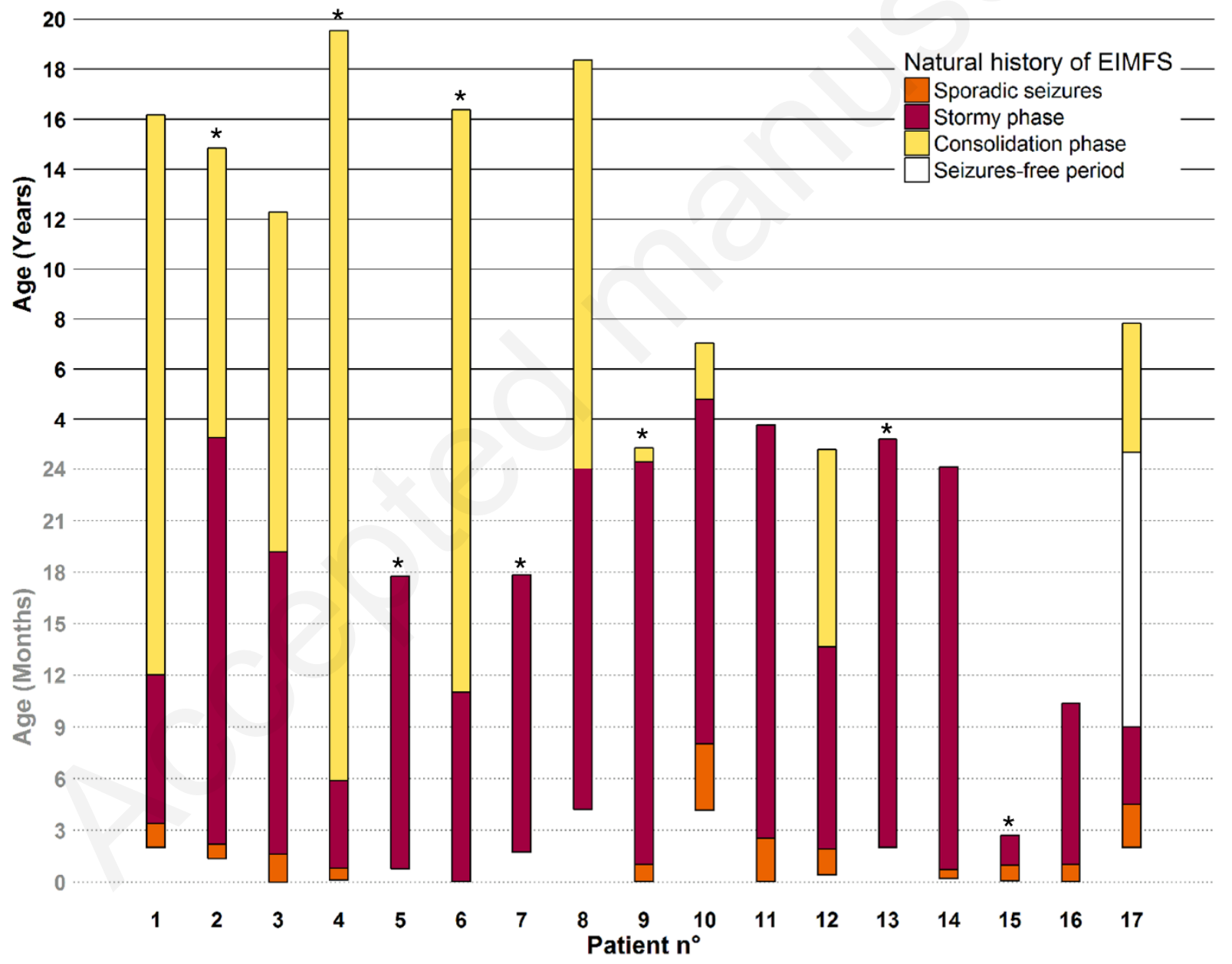

Figure 2: Evolution of EIMFS related to KCNT1 mutation 
A

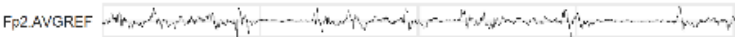
CAAVGRE Wef

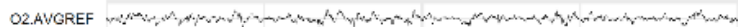

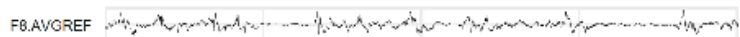

TEAVGREF

CZAVGREF W

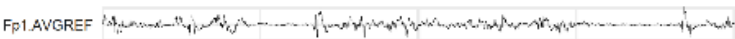

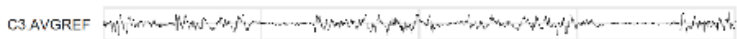

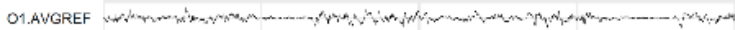

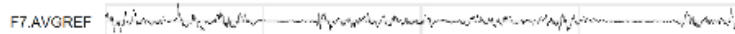

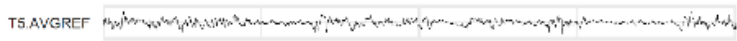

C

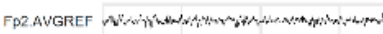

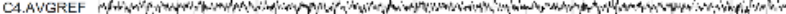

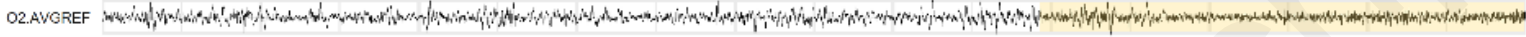

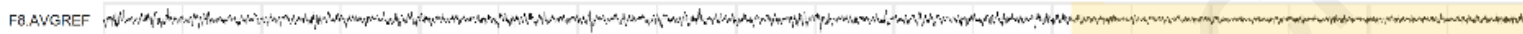

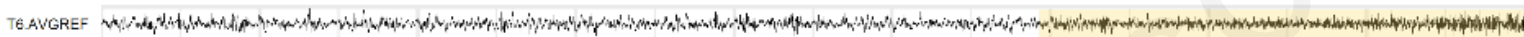

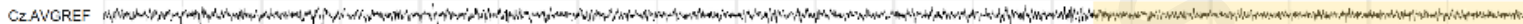

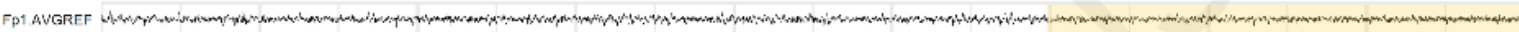

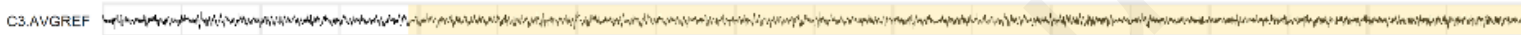

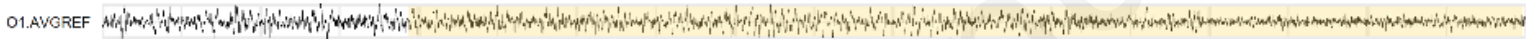

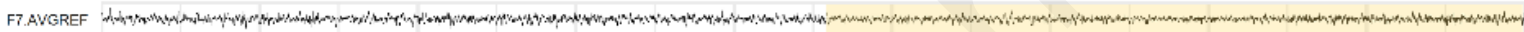

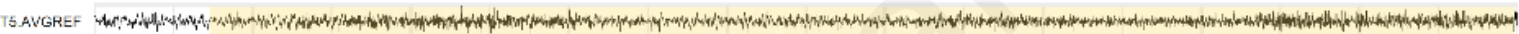

$\begin{array}{llllllllll}0 & 20 & 40 & 60 & 80 & 100 & 120 & 140 & 160\end{array}$
FP2AVGREF Now C4.AVGEF W

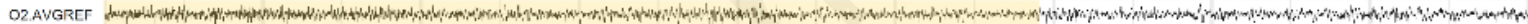

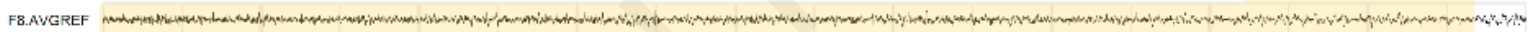

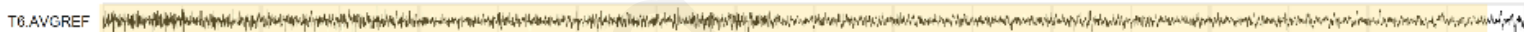

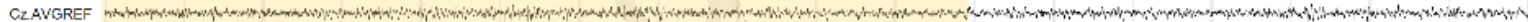

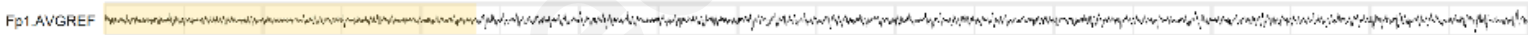

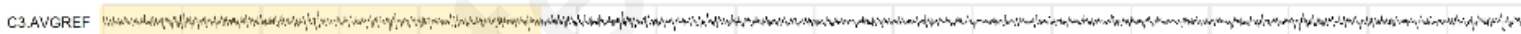

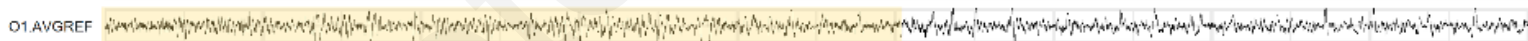

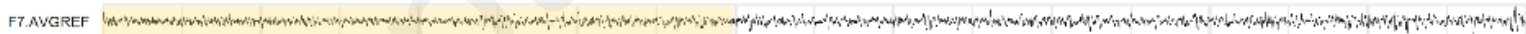

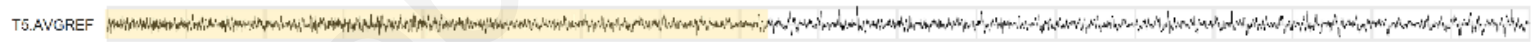
D

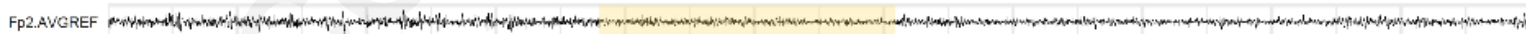

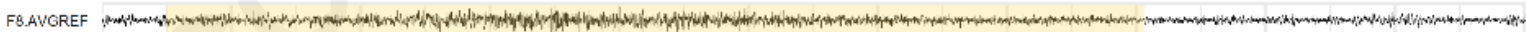

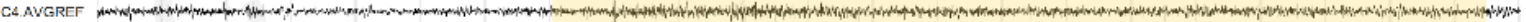

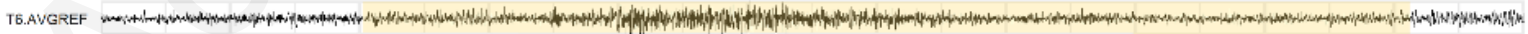
O2AVGEF Whom

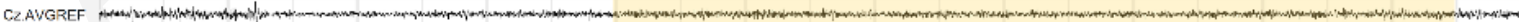
FP1.AVGREF inghw

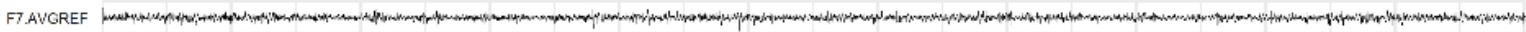

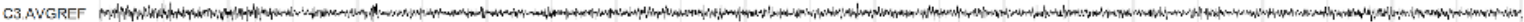

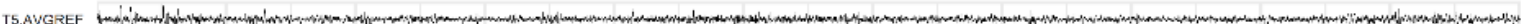

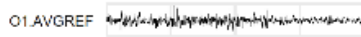

100

120

140

200 


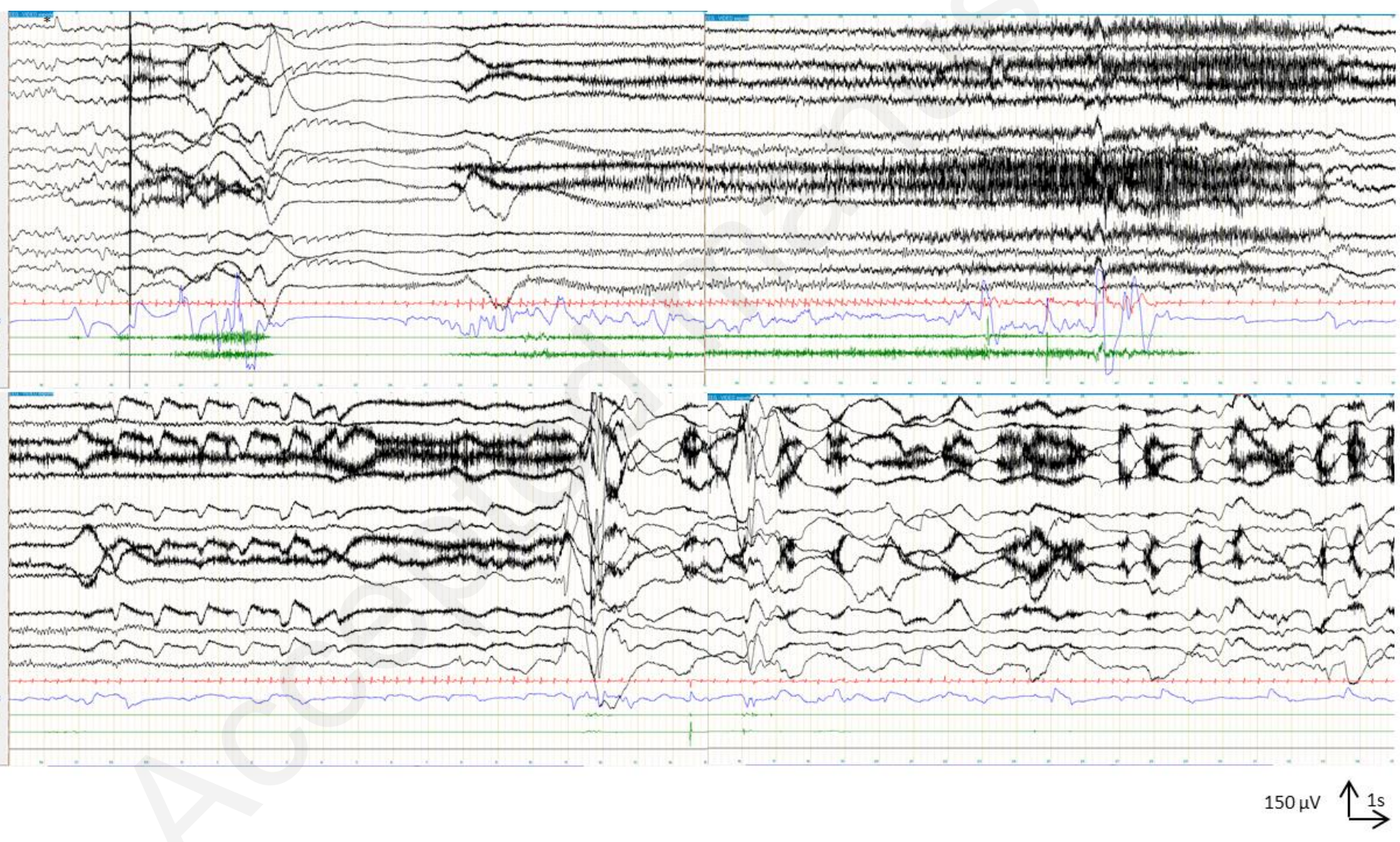

Figure 4: EEG ictal patterns at age of 7 years in the consolidation phase (patient $n^{\circ} 10$ ) 
